\title{
The investigation of direct C-glycosylation of monosaccharides under microwave activation
}

\author{
Nan Cao \\ College of Chemistry Chemical Engineering and Material Science, Zaozhuang University, China \\ caonan6746@163.com
}

\begin{abstract}
Keywords: C-glycoside; glucose; microwave; direct C-glycosylation
Abstract Carbohydrates are a class of important compounds widely occurring in nature and are the main energy source required for all living organisms. Based on the variation of glycosidic bonds in carbohydrates, they can be divided into O-glycosides, C-glycosides, thioglycosides, and other types, among which C-glycoside is an important glycoside. Research reports on C-glycosylation have noted many challenges, such as tedious steps for the synthesis of glycosyl donors, the narrow application scope of the reaction, and the low efficiency of glycosylation. In the present paper, microwaves were used to activate the direct C-glycosylation of monosaccharides. By optimizing reaction conditions, improving reaction efficiency, and investigating reaction mechanisms, we aimed to obtain an ideal C-glycosylation method.
\end{abstract}

\section{Introduction}

Along with proteins and DNA, carbohydrates are important biomacromolecules. Carbohydrate chemistry plays an extremely important role in life science and pharmaceutical research ${ }^{[1-4]}$. Based on the variation of glycosidic bonds in carbohydrates, they can be divided into O-glycosides, C-glycosides, thioglycosides, and other types, among which C-glycoside is an important glycoside. When oxygen in the O-glycosidic bond is replaced with carbon, the resulting compound is referred to as a C-glycoside ${ }^{[5]}$. Research reports of C-glycosylation have noted many challenges, such as tedious steps for the synthesis of glycosyl donors, the narrow scope of application for the reaction, and the low efficiency of glycosylation. ${ }^{[6]}$ In the present paper, microwaves were used to activate the direct C-glycosylation of monosaccharides. By optimizing reaction conditions, improving reaction efficiency, and investigating reaction mechanisms, we aimed to obtain an ideal C-glycosylation method.

\section{Experiment}

Distillation purification of acetylacetone. A total of $20 \mathrm{ml}$ of acetylacetone was added to a rounded-bottom flask, and a general distillation apparatus was conFig.d. Under magnetic stirring, acetylacetone was heated and distilled; the fraction at $140-142^{\circ} \mathrm{C}$ was collected and stored for use.

$4.00 \mathrm{~g}$ (22.2 mmol) of glucose, $7.40 \mathrm{~g}(88.8 \mathrm{mmol})$ of sodium bicarbonate, $10 \mathrm{ml}$ of tetrahydrofuran, $20 \mathrm{ml}$ of water, and $4.6 \mathrm{ml}$ ( $44 \mathrm{mmol}$ ) of newly distilled acetylacetone were added to a flask to perform the reaction. When the color of the reaction solution turned to light yellow, a condenser was connected to the flask. The setup was then placed in a microwave reactor at a temperature of $75^{\circ} \mathrm{C}$ and a power of $300 \mathrm{~W}$; the reaction lasted for $30 \mathrm{~min}$ under magnetic stirring and heating reflux.

A 10\% methanolic sulfuric acid solution was prepared and used as the chromogenic reagent. Methanol/ethyl acetate (1/6) solution was prepared and used as the developer for thin-layer chromatography (TLC). The thin-layer chromatogram is shown in Fig. 1; spot 1 corresponds to the reaction mixture and spot 2 to glucose. The TLC results indicate that glucose reacted completely. 

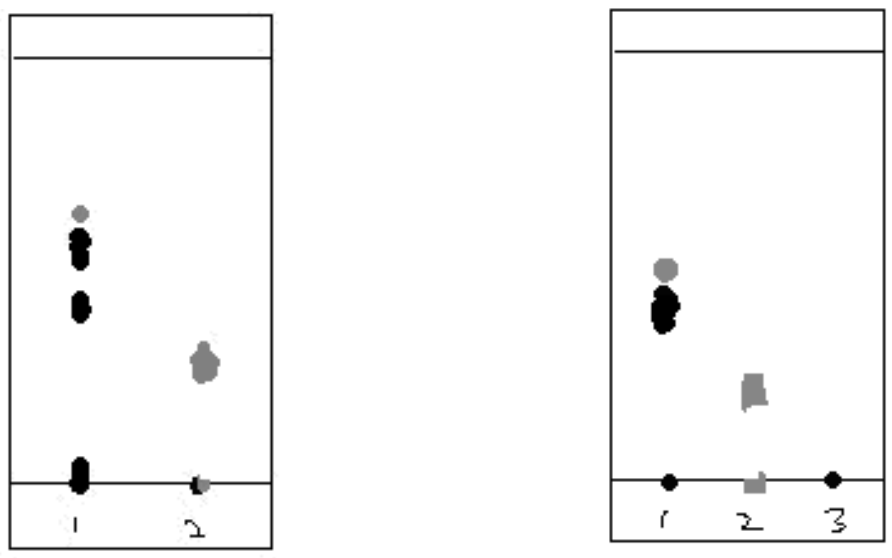

Fig. 1(left) Thin-layer chromatograms after $30 \mathrm{~min}$. Fig. 2(right) Thin-layer chromatograms of reaction mixture.
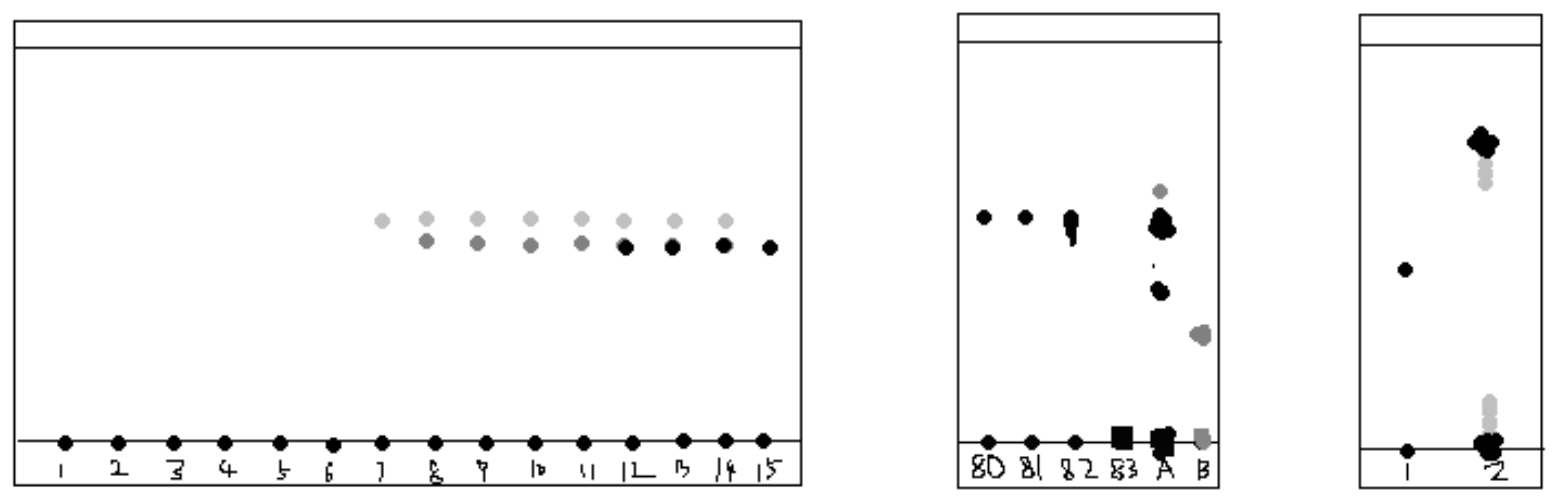

Fig. 3(left) Thin-layer chromatograms of the first 15 test tubes. Fig. 4(middle) Thin-layer chromatograms of tailing from column chromatography. Fig. 5(right) Thin-layer chromatograms after reaction for 4 hours.

Tetrahydrofuran was removed by rotary evaporation, and $20 \mathrm{ml}$ of ethyl acetate was then added for liquid separation. After the addition of water, the insoluble solid was returned to the flask; the solution was heated to $75^{\circ} \mathrm{C}$ by using a microwave reactor with a power of $300 \mathrm{~W}$ for $30 \mathrm{~min}$. This solution was gradually heated to $90^{\circ} \mathrm{C}$ and reacted for 3 hours and finally heated to $100^{\circ} \mathrm{C}$ and reacted for 2 hours $^{[7]}$.

The reaction mixture was mixed with the lower phase obtained from liquid separation; the resulting mixture was concentrated by freezing. Then, $100 \mathrm{ml}$ of methanol/ethyl acetate $(1 / 1)$ was then added to the concentrate, and the residual salt was removed by filtration. The TLC is shown in Fig. 2, in which spot 1, spot 2, and spot 3 correspond to the reaction mixture, glucose, and acetylacetone, respectively. The TLC results indicate a complete reaction.

Silica gel was added to the reaction mixture for adsorption, and the resulting solution was then spin-dried. Methanol/ethyl acetate (1/6) solution was used as the eluting agent for silica gel column chromatography. Test tubes were used to collect eluents for TLC test; the thin-layer chromatograms of the first 15 test tubes are shown in Fig. 3, where the number corresponds to the numbering of the test tubes. A sample spot started to appear from test tube 7, and pure sample appeared from test tube 15. TLC was performed in conjunction with column chromatography. Tailing in TLC appeared from test tube 82, and the sample spot disappeared from test tube 83. The TLC is shown in Fig. 4; 80, 81, 82, and 83 are the numbering of the test tubes. Spot A corresponds to the reaction mixture before column chromatography and spot B to glucose. The Fig. shows that elution was completed.

The liquid of test tubes 7 to 14 was collected, evaporated by rotovap, and concentrated; the resulting concentrate was labeled as sample I. Similarly, the liquid of test tubes 15 to 81 was collected, evaporated by rotovap, and concentrated; the resulting concentrate was labeled as sample II. Ethanol was used to re-crystallize samples I and II, and activated carbon was added to adsorb its color. Rotary evaporation was used to recrystallize and spin-dry samples I and II. The resulting samples were dried 
in a vacuum oven for 12 hours to obtain a colorless syrup-like material. The samples were weighed at $0.5021 \mathrm{~g}$ for sample I and $3.1669 \mathrm{~g}$ for sample II; the total mass was $3.6690 \mathrm{~g}$. The above steps were repeated using different reaction conditions to optimize the process.

The C-glycosylation was repeated: $10 \mathrm{~g}$ of the reaction mixture before column chromatography, $50 \mathrm{ml}$ of acetic anhydride, and $10 \mathrm{~g}$ of sodium acetate were added to flask, magnetically stirred, and heat refluxed; the temperature was $80^{\circ} \mathrm{C}$, and the reaction lasted for 4 hours. TLC was performed for the reaction mixture, and the results are shown in Fig. 5; spot 1 corresponds to pure C-glycoside and spot 2 to acetylated mixture compounds. The Fig. shows that the reaction went to completion.

The reaction mixture was poured into an ice and water mixture for washing while it was still hot. The solution was stirred using a glass rod for approximately $30 \mathrm{~min}$ and filtered. Water washing and filtration were repeated twice. Ethanol (50\%) was used for heat refluxing for 1 hour. The resulting solution was recrystallized, activated carbon was added to adsorb color, and the solution was filtered while still hot. The heat reflux was repeated, and the resulting solution was filtered, cooled to recrystallize, and vacuum dried for 12 hours, yielding white crystals. A melting point of $113-115^{\circ} \mathrm{C}$ was measured using a melting point apparatus.

\section{Results and Discussion}

A small spot appeared above spots 1 in both Fig. 1 (thin-layer chromatogram after $30 \mathrm{~min}$ ) and Fig. 2 (thin-layer chromatogram of mixture after completion of reaction), corresponding to isomers of C-glycosides. Similarly, in Fig. 3 (the thin-layer chromatograms of the first 15 test tubes), for test tubes 7 to 14, the spot above spot 1 also corresponds to the isomers of C-glycosides.

Sample II was characterized by FTIR, and the spectrum is shown in Fig. 6. The main absorption peaks are assigned as follows: $3397.2 \mathrm{~cm}^{-1}(-\mathrm{OH}), 2929.0 \mathrm{~cm}^{-1}$ (-C-H in methyl and methylene groups), $1703.7 \mathrm{~cm}^{-1}(\mathrm{C}=\mathrm{O}), 1423.4 \mathrm{~cm}^{-1}\left(\delta \mathrm{CH}\right.$ in methylene group), $1361.7 \mathrm{~cm}^{-1}(\delta \mathrm{CH}$ in methine group), $1386.9 \mathrm{~cm}^{-1}$ ( $\delta \mathrm{sCH}$ in methyl group), $1084.1 \mathrm{~cm}^{-1}$ (vasC-O-C in ether group), $1044.9 \mathrm{~cm}^{-1}$ ( $v \mathrm{C}-\mathrm{O}$ in $\left.\mathrm{R}^{-} \mathrm{CH}_{2}-\mathrm{OH}\right)$.

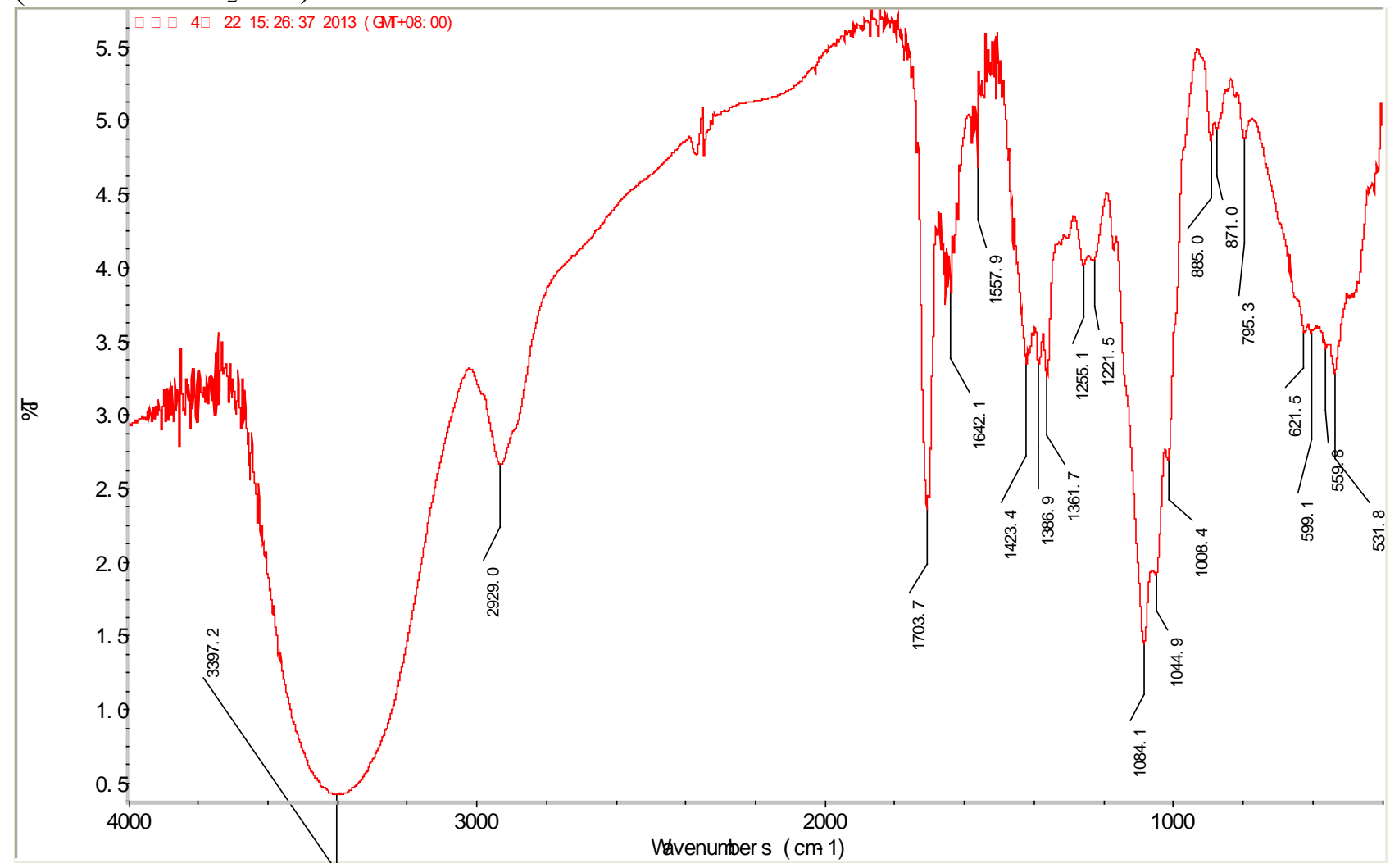

Fig. 6 FTIR spectrum of C-glycosides.

The raw material, glucose, was characterized by FTIR, and the spectrum is shown in Fig. 7. The main absorption peaks are assigned as follows: $3391.6 \mathrm{~cm}^{-1}(-\mathrm{OH}), 3321.65 \mathrm{~cm}^{-1}(\mathrm{vOH}$ in $-\mathrm{OH}), 2943.0$ $\mathrm{cm}^{-1}$ (-C-H in methylene and methine groups), $1454.2 \mathrm{~cm}^{-1}$ ( $\delta \mathrm{CH}$ in methylene group), $1378.5 \mathrm{~cm}^{-1}$ 
( $\delta \mathrm{CH}$ in methine group), $1145.8 \mathrm{~cm}^{-1}$ (vasC-O-C in ether group), $1103.7 \mathrm{~cm}^{-1}\left(v \mathrm{C}-\mathrm{O}\right.$ in $\mathrm{R}_{2}-\mathrm{CH}-\mathrm{OH}$ ), $1156.1 \mathrm{~cm}^{-1}$ ( $v \mathrm{C}-\mathrm{O}$ in $\left.\mathrm{R}-\mathrm{CH}_{2}-\mathrm{OH}\right)$.

The FTIR spectra of C-glycosides and glucose were compared, as shown in Fig. 8. The comparison indicates that the hydroxyl peak was pronounced in C-glycoside but not present in glucose, indicating that the product of the reaction was C-glycoside.

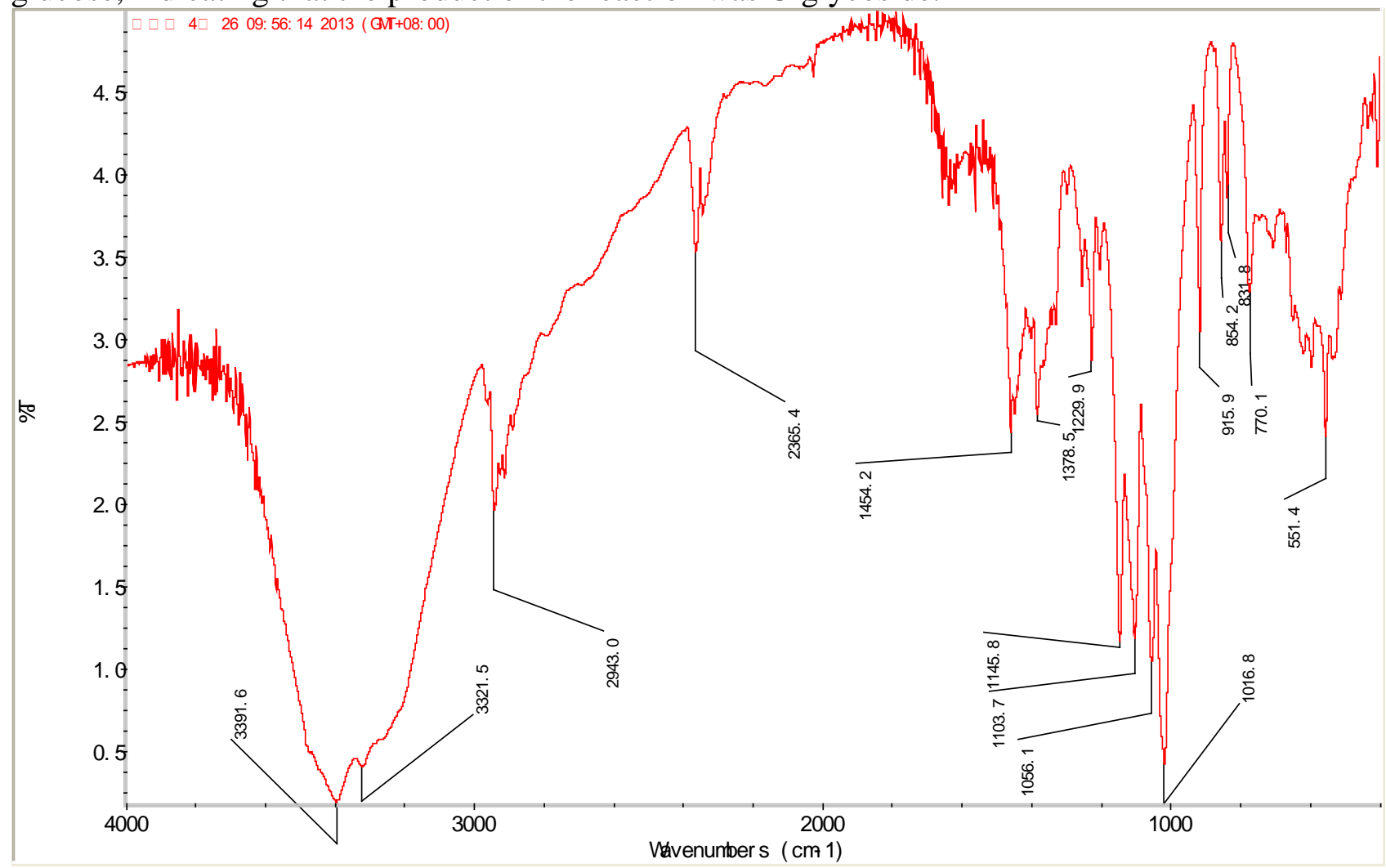

Fig. 7 FTIR spectrum of glucose

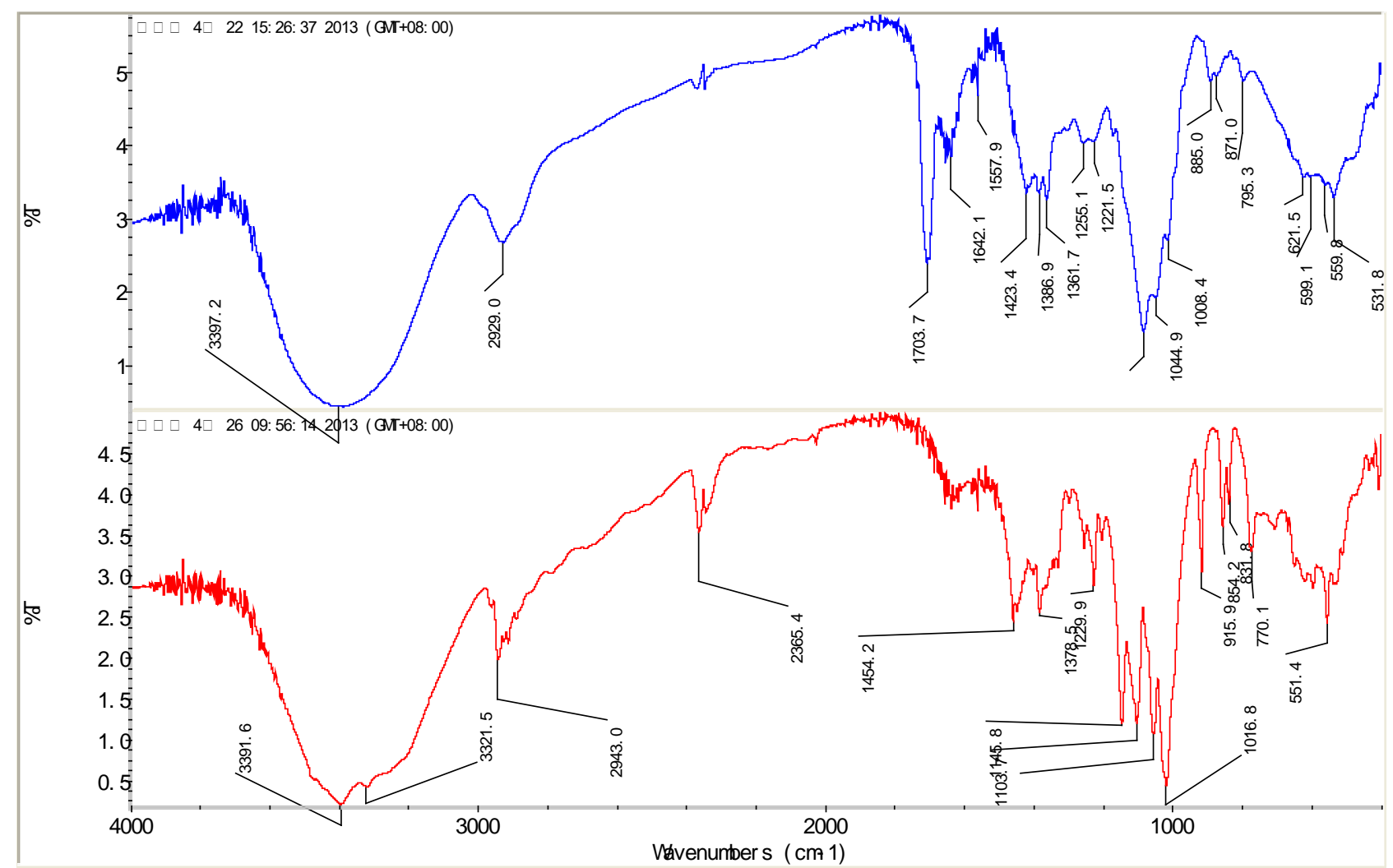

Fig. 8 Comparison of FTIR spectra of C-glycoside and glucose. 


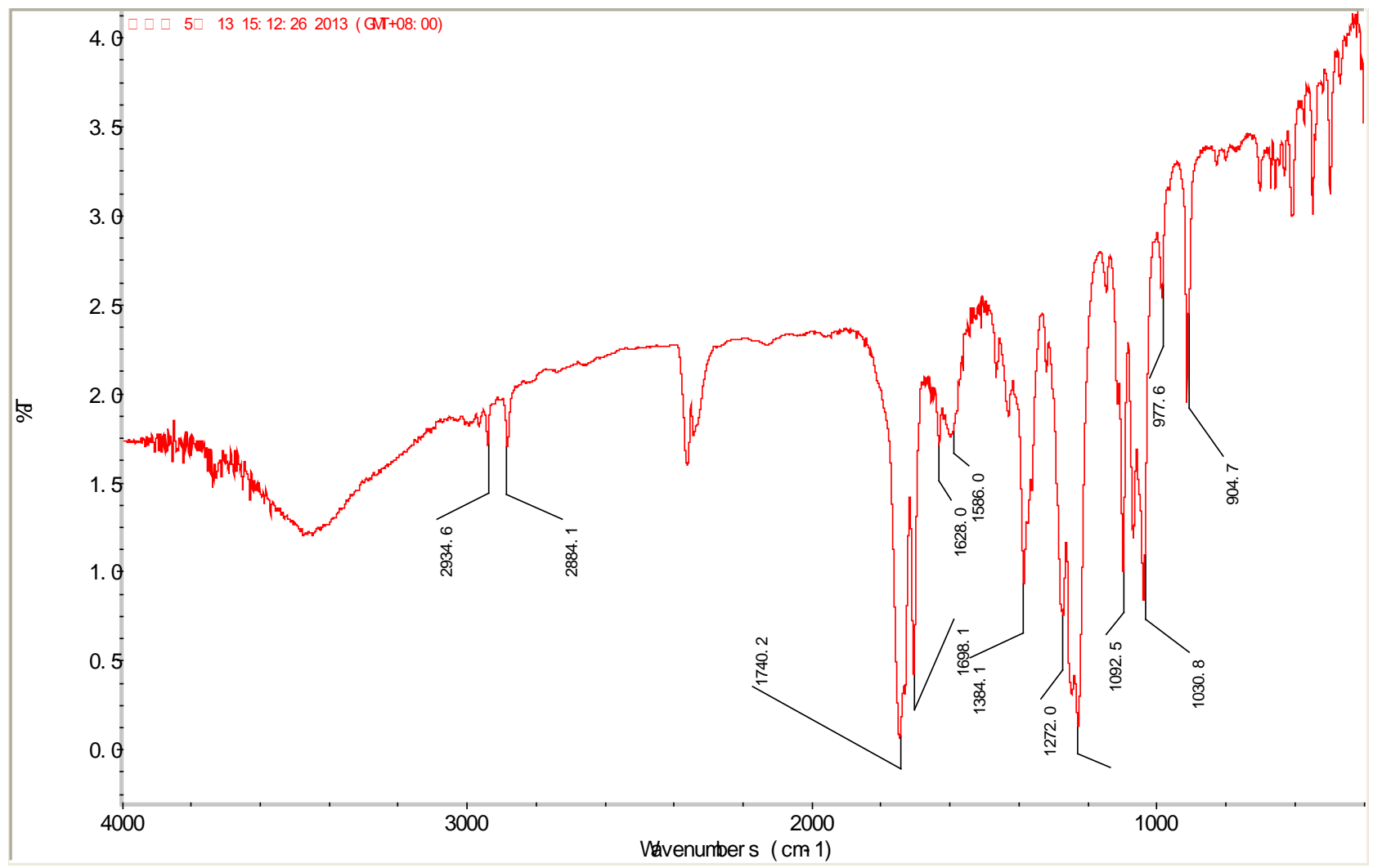

Fig. 9 FTIR spectrum of acetylated C-glycosides.

The acetylated C-glycosides were characterized by FTIR, and the spectrum is shown in Fig. 9. The main absorption peaks are assigned as follows: $2934.6 \mathrm{~cm}^{-1}$ (vas $\mathrm{CH}$ in methylene group), 2884.1 $\mathrm{cm}^{-1}$ ( $\mathrm{vsCH}$ in methyl, methylene, methine groups), $1740.2 \mathrm{~cm}^{-1}$ (C=O in ester group), $1698.1 \mathrm{~cm}^{-1}$ ( $\mathrm{C}=\mathrm{O}$ in $\mathrm{C}$-glycoside), $1384.1 \mathrm{~cm}^{-1}\left(\delta \mathrm{sCH}\right.$ in methyl group), $1272.0 \mathrm{~cm}^{-1}$ and other unassigned, adjacent absorption peaks ( $\mathrm{vC}-\mathrm{O}-\mathrm{C}$ in ester bond), $1092.5 \mathrm{~cm}^{-1}$ (vasC-O-C in ether bond).

The molecular weight of acetylated C-glycosides is 220 . Because the theoretical yield from $4 \mathrm{~g}$ of glucose is $4.8889 \mathrm{~g}$, the actual yield is $75.05 \%((3.6690 \div 4.8889) \times 100 \%)$.

The reaction conditions were varied, and the data for the varied reactions are shown in tables 1 , 2 , and 3 . In table 1, the reaction time and amount of reactants were kept the same to investigate the optimum reaction power; in table 2 , the reaction power and amount of reactant were kept the same to investigate the optimum reaction time; in table 3 , the reaction power and reaction time were kept the same to investigate the optimum molar ratios of the reactants. Because the temperature is related to the ratio of reactants and reaction power, it was not independently studied. The three tables show that the highest yield was $75.05 \%$ and that the yields of other reactions were all less than $75.05 \%$. Therefore, the optimum reaction conditions are as follows: $4.00 \mathrm{~g}(22.2 \mathrm{mmol})$ of glucose; $7.40 \mathrm{~g}$ ( $88.8 \mathrm{mmol}$ ) of sodium bicarbonate; $10 \mathrm{ml}$ of tetrahydrofuran, $20 \mathrm{ml}$ of water; $4.6 \mathrm{ml}$ (44 mmol) of acetylacetone, i.e., glucose/acetylacetone/tetrahydrofuran $=1 / 2 / 4$; a power of $300 \mathrm{~W}$; a temperature of $75^{\circ} \mathrm{C}$; and a reaction time of $30 \mathrm{~min}$.

Table 1 The effect of reaction power on the yield.

\begin{tabular}{ccccccccc}
\hline Power (W) & 300 & 400 & 500 & 600 & 700 & 800 & 900 & 1000 \\
\hline Time (min) & 30 & 30 & 30 & 30 & 30 & 30 & 30 & 30 \\
Glucose (g) & 4.00 & 4.00 & 4.00 & 4.00 & 4.00 & 4.00 & 4.00 & 4.00 \\
Acetylacetone (ml) & 4.6 & 4.6 & 4.6 & 4.6 & 4.6 & 4.6 & 4.6 & 4.6 \\
Sodium bicarbonate (g) & 7.40 & 7.40 & 7.40 & 7.40 & 7.40 & 7.40 & 7.40 & 7.40 \\
Yield (\%) & 75.05 & 73.12 & 72.07 & 70.69 & 70.00 & 68.50 & 65.36 & 62.19 \\
\hline
\end{tabular}


Table 2 The effect of the reaction time on the yield.

\begin{tabular}{ccccccccc}
\hline Time (min) & 24 & 26 & 28 & 30 & 32 & 34 & 36 & 38 \\
\hline Power (W) & 300 & 300 & 300 & 300 & 300 & 300 & 300 & 300 \\
Glucose (g) & 4.00 & 4.00 & 4.00 & 4.00 & 4.00 & 4.00 & 4.00 & 4.00 \\
Acetylacetone (ml) & 4.6 & 4.6 & 4.6 & 4.6 & 4.6 & 4.6 & 4.6 & 4.6 \\
Sodium bicarbonate (g) & 7.40 & 7.40 & 7.40 & 7.40 & 7.40 & 7.40 & 7.40 & 7.40 \\
Yield (\%) & 70.05 & 71.12 & 73.16 & 75.05 & 74.33 & 73.91 & 73.00 & 72.25 \\
\hline
\end{tabular}

Table 3 The effect of reactant ratio on the yield.

\begin{tabular}{ccccccccc}
\hline Glucose (g) & 4.00 & 8.00 & 4.00 & 4.00 & 4.00 & 4.00 & 4.00 & 4.00 \\
\hline Acetylacetone (ml) & 4.6 & 4.6 & 6.9 & 2.3 & 4.6 & 4.6 & 4.6 & 4.6 \\
Sodium bicarbonate (g) & 7.40 & 7.40 & 7.40 & 7.40 & 3.70 & 5.55 & 9.25 & 11.10 \\
Power (W) & 300 & 300 & 300 & 300 & 300 & 300 & 300 & 300 \\
Time (min) & 30 & 30 & 30 & 30 & 30 & 30 & 30 & 30 \\
Yield (\%) & 75.05 & 74.72 & 74.90 & 50.93 & 62.23 & 68.53 & 74.36 & 74.69 \\
\hline
\end{tabular}

\section{Summary}

In microwave reactions, higher power does not necessarily lead to higher yield. In addition, temperature also affects yield. Therefore, there exists an optimum reaction power and temperature in the microwave reaction, which were $300 \mathrm{~W}$ and $75^{\circ} \mathrm{C}$, respectively, in the present study. In chemical reactions, the ratio of reactants also plays an important role because most chemical reactions are reversible. To increase better and higher yield, it is advisable to increase the amount of reactants. As shown in the present study, the optimum ratio of reactants was 1/2/4 for glucose, acetylacetone, and sodium bicarbonate, respectively. Increased scientific understanding has led to better recognition of the important role of carbohydrates and their essential nature. As one of the important reactions involving carbohydrates, C-glycosylation is expected to receive further attention and will be used in wider applications to improve public health.

\section{References}

[1] T. Baran, E. Açiksöz and A. Menteş: Carbohyd. Polym. Vol. 142 (2016), p. 189

[2] D. Mu, J.Q. Li and S.Y. Feng: Phys. Chem. Chem. Phys. Vol. 17 (2015), p. 12492

[3] D. Mu, J.Q. Li and S.Y. Feng: Soft Matter Vol. 11 (2015), p. 4366

[4] D. Mu, J.Q. Li and S.Y. Feng: Soft Matter Vol. 11 (2015), p. 4356

[5] F. Israr, D. Chun, Y. Kim and D.K. Kim: Ultrason. Sonochem. Vol. 31 (2016), p. 93

[6] N. Rostamizadeh, A.K. Amiri and H. Moghanian: Synth. React. Inorg. M. Vol. 46 (2016), p. 631

[7] Y.Z. Zhang, Y.J. Wu, Q.D. Qin, F.C. Wang and D. Chen: J. Magn. Magn. Mater. Vol. 409 (2016), p. 6 